\title{
ASSESSMENT OF TOXIC METALS IN SEDIMENTS OF MERIÇ, TUNCA AND ERGENE RIVERS BY USING BIOLOGICAL AND ECOLOGICAL RISK INDICES
}

\author{
Cem Tokatli ${ }^{1}$, Yasin Baștatli ${ }^{2}$
}

\begin{abstract}
The Meriç River, the longest river of the Balkans, is the most important aquatic ecosystem within the Thrace Region of Turkey, along with its main tributaries, the Tunca and Ergene Rivers. In this study, the sediment quality of Meriç, Tunca, and Ergene Rivers was evaluated by using the Potential Ecological Risk Index (RI) and the Biological Risk Index (mERM-Q), both widely used methods in sediment quality assessment studies, to assess the ecological and biological risks of heavy metals within the river ecosystems. According to the results of the Biological Risk Index, nickel and chromium displayed the highest risk factors, and in terms of the Potential Ecological Risk Index, cadmium yielded the highest risk factor across all the investigated lotic ecosystems.
\end{abstract}

UDC Classification: 556.5 DOI: http://dx.doi.org/10.12955/cbup.v4.851

Keywords: Meriç River, Tunca River, Ergene River, Sediment Quality, Bio-Ecological Risk Indices.

\section{Introduction}

Heavy metals are among the most important environmental pollutants globally and these are often discharged into aquatic ecosystems in significant quantities. They can accumulate or be biomagnified along the aquatic food chain, via water and sediment pathways. It is well known that sediments are a sink for various contaminants that can pose a serious risk to water quality (Farombi, et al., 2007; Massoudieh et al., 2010; Yu et al., 2011). The Potential Ecological Risk Index (RI) and the Biological Risk Index based sediment quality guidelines (mERM-Q) are two of the most widely used indices for evaluating environmental risks in terms of sediment contamination (Çiçek et al., 2013).

Meriç River, the longest river of the Balkans, flows through Turkish territory, with Turkey on both sides, and then forms the border between Greece and Turkey, with Greece on the west bank and Turkey on the east bank, before flowing to the Aegean Sea. The Tunca and Ergene Rivers are the most important branches of the Meriç River and these are potentially exposed to intensive organic and inorganic pollution (Tokatl, 2015).

The aim of the present study is to evaluate the sediment quality of Meriç, Ergene, and Tunca Rivers by using RI and mERM-Q methods to investigate arsenic, nickel, chromium, lead, cadmium, zinc, and copper concentrations in sediment samples.

\section{Materials and Methods}

Study Area and Collection of Samples

Sediment samples were collected in autumn 2015 from downstream stations in each of the three rivers: Meriç, Tunca, and Ergene, using an Ekman grab to sample sediment and by taking small portions from the center of the dipper and grab, with a polyethylene spoon, to avoid contamination by metallic parts of the grab. The coordinate details, explanatory information, and localities of selected stations are given in Table 1, and the map of study area is shown in Figure 1.

\section{Chemical Analysis}

Sediment samples were dried for 3 hours at $105{ }^{\circ} \mathrm{C}$ for element analyses. Then, all sediment samples were placed ( $0.25 \mathrm{~g}$ of each sample) in Pyrex reactors of a CEM Mars Xpress 5 microwave digestion unit. $\mathrm{HClO} 4: \mathrm{HNO} 3$ acids in 1:3 proportions were inserted in each reactor. Samples were mineralized at $200{ }^{\circ} \mathrm{C}$ for thirty minutes, after which the samples were filtered in such a way as to make up their volumes to $100 \mathrm{ml}$ with ultra-pure distilled water.

\footnotetext{
${ }^{1}$ Cem Tokatli, Trakya University, Ipsala Vocational School, Department of Laboratory Technology, İpsala/Edirne, Turkey, tokatlicem@gmail.com

${ }^{2}$ Yasin Baştatli, Dumlupınar University, Faculty of Science, Department of Biology, Kütahya, Turkey,

yasinbastatli@gmail.com
} 


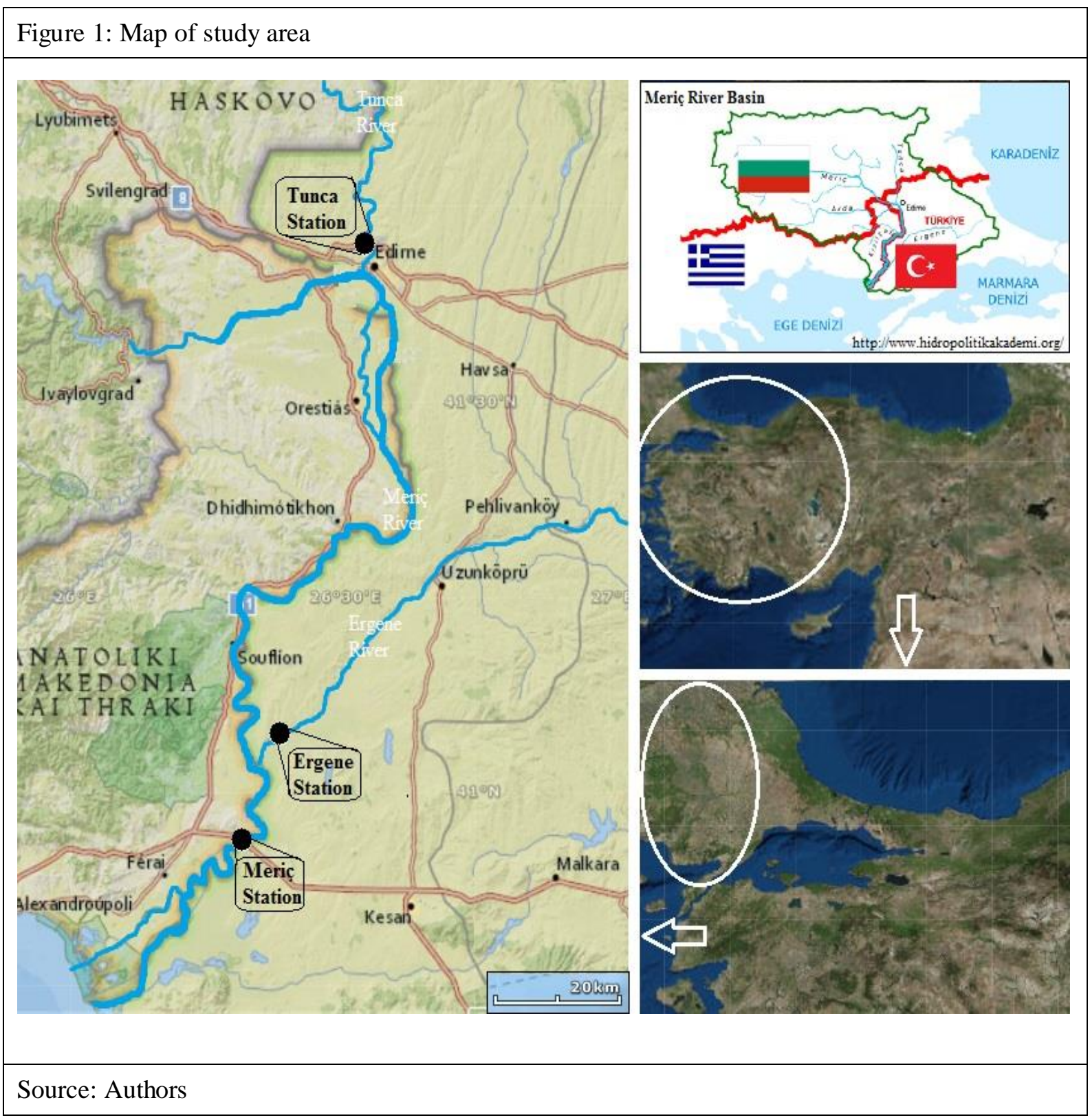

\begin{tabular}{|c|cccc|}
\hline \multicolumn{3}{|l}{ Table 1: Localities of selected stations } \\
\hline \multirow{3}{*}{ Station } & \multirow{4}{4}{ Coordinates } & \\
\cline { 2 - 5 } & Locality & North & South & \multirow{2}{*}{ Explanation } \\
& & (DD. & $-\quad$ (DD. & \\
\hline Tunca River & Edirne Province & 41.66850 & 26.55413 & Downstream site of Tunca River \\
\hline Ergene River & Uzunköprü District & 41.28291 & 26.69906 & Downstream site of Ergene River \\
\hline Meriç River & İpsala District & 40.94654 & 26.36079 & $\begin{array}{c}\text { Downstream site of Meriç River } \\
\text { (after junction with Ergene and Tunca Rivers) }\end{array}$ \\
\hline
\end{tabular}

Source: Author

Element concentrations were determined by Inductively Coupled Plasma-Optic Emission Spectrophotometric (Varian 720 ES) method in the TUTAGEM laboratory of Trakya University. The results of the element analyses were recorded as means of triplicate measurements (EPA, 1998; EPA, 2001). 
Sediment Quality Indices

1. Potential Ecological Risk Index (RI)

This index was developed to evaluate ecological risk as a way of understanding and managing aquatic pollution. The methodology is based on the assumption that the sensitivity of the aquatic system depends on its productivity. It was introduced to evaluate the degree of toxic metal pollution in sediments, according to the toxicity of toxic metals and the response of the environment. This index can be calculated using the following formula (Hakanson, 1980):

$$
\begin{aligned}
& R_{\mathrm{I}}=\sum E_{r}^{i} \\
& E_{r}^{i}=T_{r}^{i} C_{f}^{i} \\
& C_{f}^{i}=C_{0}^{i} / C_{n}^{i}
\end{aligned}
$$

Where

" $\mathrm{R}_{\mathrm{I}}$ " is the sum of all risk factors for heavy metals in the sediments;

" $\mathrm{E}_{\mathrm{r}}^{\mathrm{i}}$ " is the potential ecological risk for monomial factors;

" $\mathrm{T}_{\mathrm{r}}^{\mathrm{i}}$ " is the toxic response factor for a given substance (Table 2);

" $\mathrm{C}_{\mathrm{f}}^{\mathrm{i}}$ " is the contamination factor, " $\mathrm{C}{ }_{0}^{\mathrm{i}}$ " is the concentration of metals in the sediment; and " $\mathrm{C}_{\mathrm{n}}^{\mathrm{i}}$ " is a reference value for metals (Table 2).

Table 2: Reference values $\left(\mathrm{C}_{\mathrm{n}}^{\mathrm{i}}\right)$ and toxicity coefficients $\left(\mathrm{T}_{\mathrm{r}}^{\mathrm{i}}\right)$ for the sum of all risk factors $\left(\mathrm{R}_{\mathrm{I}}\right)$, and the effect range low (ERL) and effect range median (ERM) values of heavy metals in sediment

\begin{tabular}{|c|r|r|r|r|}
\hline \multirow{2}{*}{ Elements } & \multicolumn{2}{|c|}{$\mathbf{R}_{\mathbf{I}}$} & \multicolumn{3}{|c|}{ mERM-Q } \\
\cline { 2 - 5 } & $\mathrm{C}_{\mathrm{i}_{n}}$ & $\mathrm{~T}_{\mathrm{i}} \mathrm{i}_{\mathrm{r}}$ & \multicolumn{1}{|c|}{ ERL } & \multicolumn{2}{|c|}{ ERM } \\
\hline $\mathrm{As}$ & 15.00 & 10.00 & 33.00 & 85.00 \\
\hline $\mathrm{Cr}$ & 60.00 & 2.00 & 80.00 & 145.00 \\
\hline $\mathrm{Cu}$ & 30.00 & 5.00 & 70.00 & 390.00 \\
\hline $\mathrm{Pb}$ & 25.00 & 5.00 & 35.00 & 110.00 \\
\hline $\mathrm{Zn}$ & 80.00 & 1.00 & 120.00 & 270.00 \\
\hline
\end{tabular}

Source: Hilton, Davison, \& Ochsenbein (1985), EPA (2005)

\begin{tabular}{|c|c|c|c|c|c|}
\hline \multicolumn{4}{|c|}{ Assessment of potential ecological risk } & \multicolumn{2}{|c|}{$\begin{array}{c}\text { Assessment of biological } \\
\text { risk }\end{array}$} \\
\hline$E_{r}^{i}$ & $\begin{array}{l}\text { Monomial } \\
\text { - factors }\end{array}$ & $\mathrm{R}_{\mathrm{I}}$ & $\begin{array}{l}\text { Multinomial } \\
\text { factors }\end{array}$ & $\begin{array}{l}\text { ERM-Qi } \\
\text { and } \\
\text { mERM-Q }\end{array}$ & $\begin{array}{c}\text { Monomial } \\
\text { and } \\
\text { multinomial } \\
\text { factors }\end{array}$ \\
\hline$<40$ & Low & $<95$ & Low & $<0.1$ & Low priority \\
\hline $40-80$ & Moderate & $95-190$ & Moderate & $0.1-0.5$ & $\begin{array}{l}\text { Medium-low } \\
\text { priority }\end{array}$ \\
\hline $80-160$ & Considerable & $\begin{array}{c}190- \\
380\end{array}$ & Considerable & $0.5-1.5$ & $\begin{array}{l}\text { High-medium } \\
\text { priority }\end{array}$ \\
\hline $\begin{array}{c}160- \\
320\end{array}$ & High & $>380$ & Very high & $>1.5$ & High priority \\
\hline$>320$ & Very high & & & & \\
\hline
\end{tabular}

The scale of " $\mathrm{R}_{\mathrm{I}}$ " is given in Table 3 .

Table 3: Scale used to describe the risk factors of $\mathrm{E}_{\mathrm{r}}^{\mathrm{i}}, \mathrm{R}_{\mathrm{I}}, \mathrm{ERM}-\mathrm{Q}_{\mathrm{i}}$, and mERM-Q

Source: Hakanson (1980), Long, Ingersoll, \& MacDonald (2005) 


\section{Biological Risk Index (mERM-Q)}

The sediment quality guidelines (SQGs) that are used in this index are based on results from biological toxicity testing within benthic environments. These guidelines are classified by three levels, using ERL (effect range low) and ERM (effect range median), as rarely $(<\mathrm{ERL}$ ), occasionally (ERL $-E R M)$, and frequently $(\geq E R M)$ in terms of adverse biological effects (EPA, 2005). A mean effects range-median quotient (mERM-Q) has been proposed as a biological risk index for evaluating the potential effects of multiple toxic metal contamination of sediment. This index can be calculated using the following formula (Long, Ingersoll, \& MacDonald, 2005):

$$
\begin{aligned}
& m E R M-Q=\left(\sum_{i=1}^{n} E R M-Q_{i}\right) / n \\
& E R M-Q_{i}=C_{i} / E R M_{i}
\end{aligned}
$$

Where

"mERM-Q" is the effect range median quotient of multiple-metal contamination;

" $\mathrm{C}$ " ' is the total content of selected metal;

"ERM" is the ERM value of selected metal (Table 2); and

" $n$ " is the number of selected metals.

The scale of " $m E R M-Q$ " is given in Table 3 .

\section{Results and Discussion}

The potential ecological risk factors, monomial $\left(\mathrm{E}_{\mathrm{r}}^{\mathrm{i}}\right)$ and multinomial $\left(\mathrm{R}_{\mathrm{I}}\right)$, and the biological risk factors, monomial (ERM-Qi) and multinomial (mERM-Q), for all the investigated rivers, are shown in Table 4.

\begin{tabular}{|c|c|c|c|c|c|c|c|}
\hline \multicolumn{7}{|c|}{$\mathbf{E}_{r}^{i}$} & \multirow{2}{*}{$\mathbf{R}_{\mathbf{I}}$} \\
\hline As & $\mathrm{Cr}$ & $\mathbf{C u}$ & $\mathbf{P b}$ & $\mathbf{Z n}$ & Cd & $\mathbf{N i}$ & \\
\hline 0.071 & 0.042 & 0.038 & 0.048 & 0.011 & 0.216 & 0.064 & 0.490 \\
\hline 0.166 & 0.087 & 0.107 & 0.207 & 0.042 & 1.440 & 0.107 & 2.155 \\
\hline 0.224 & 0.114 & 0.265 & 0.409 & 0.048 & 1.267 & 0.194 & 2.521 \\
\hline \multicolumn{7}{|c|}{ ERM-Q ${ }_{i}$} & \multirow{2}{*}{ mERM-Q ${ }_{i}$} \\
\hline As & $\mathrm{Cr}$ & $\mathbf{C u}$ & $\mathbf{P b}$ & $\mathbf{Z n}$ & Cd & $\mathbf{N i}$ & \\
\hline 0.001 & 0.009 & 0.001 & 0.002 & 0.003 & 0.000 & 0.011 & 0.004 \\
\hline 0.003 & 0.018 & 0.002 & 0.009 & 0.012 & 0.003 & 0.018 & 0.009 \\
\hline 0.004 & 0.024 & 0.004 & 0.019 & 0.014 & 0.002 & 0.032 & 0.014 \\
\hline
\end{tabular}

Table 4: Toxic metal risk indices values

$\mathrm{E}_{\mathrm{r}}^{\mathrm{i}}$ is the monomial and $\mathrm{R}_{\mathrm{I}}$ is the multinomial heavy metal potential ecological risk index ERM-Q $i$ is the monomial and mERM-Q is the multinomial biological risk index

Source: Authors

According to the results of monomial potential ecological risk indices $\left(\mathrm{E}_{\mathrm{r}}^{\mathrm{i}}\right)$, cadmium posed the highest ecological risk in general. The potential ecological risk indices for monomial regulators indicated that the intensity of the investigated toxic metals was in the order of $\mathrm{Cd}>\mathrm{Pb}>\mathrm{As}>\mathrm{Cu}>\mathrm{Ni}>\mathrm{Cr}>\mathrm{Zn}$.

According to the results of multinomial potential ecological risk indices $\left(\mathrm{R}_{\mathrm{I}}\right)$, all the investigated stations exhibited low ecological risk. The potential ecological risk indices for multinomial regulators indicated that the level of ecological risk for the investigated systems was in the order of Ergene River $>$ Meriç River $>$ Tunca River (Figure 2).

Cadmium is a toxic metal that is readily emitted to soil and water through the application of phosphate-containing fertilizers in agricultural practices. Cadmium is known to accumulate in aquatic 
organisms as well as in agricultural crops (ATSDR, 2007) and intensive agricultural applications are known within the Meriç River Basin. In the present study, the RI results showed cadmium as the heavy metal of most concern in terms of ecological risk within the region.

Figure 2: Values of Potential Ecological Risk Index (RI) for heavy metals within the Thrace rivers

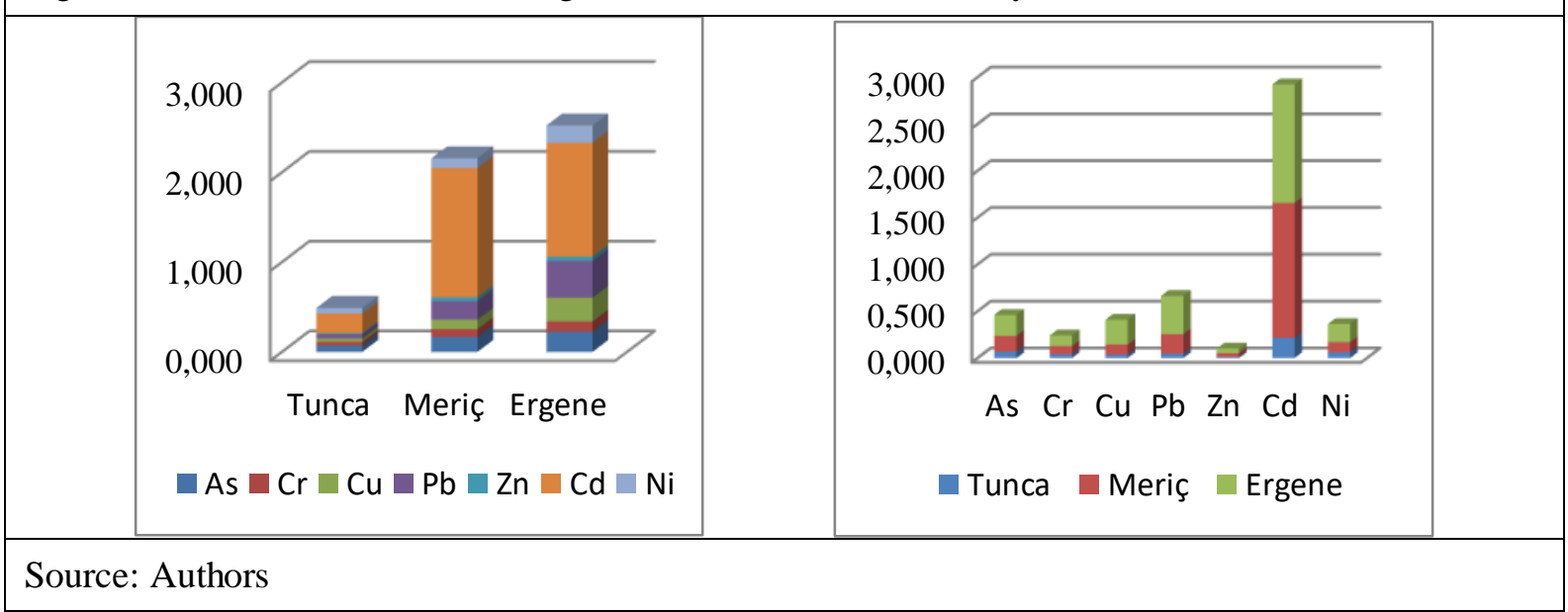

According to the results of monomial biological risk indices (ERM-Qi), chromium and nickel posed the highest biological risk in general. The biological risk indices for monomial regulators indicated the intensity of the investigated toxic metals was in the order of $\mathrm{Ni}>\mathrm{Cr}>\mathrm{Pb}>\mathrm{Zn}>\mathrm{As}>\mathrm{Cu}>\mathrm{Cd}$.

According to the results of multinomial biological risk indices (mERM-Q), all the investigated stations exhibited "low priority". The biological risk indices for multinomial regulators indicated the level of biological risk within the system was in the order of Ergene River $>$ Meriç River $>$ Tunca River (Figure 3).

Chromium and nickel occur naturally in the Earth's crust and enter the environment from natural processes as well as from human activities (ATSDR, 2005; ATSDR, 2008). The Ergene River is exposed to potential contamination because of intensive industrial activity. In the present study, the $\mathrm{mERM}-\mathrm{Q}$ revealed chromium and nickel were heavy metals of most concern in terms of biological risk within the region.

Figure 3: Values of Biological Risk Index (mERM-Q) for heavy metals within the Thrace rivers

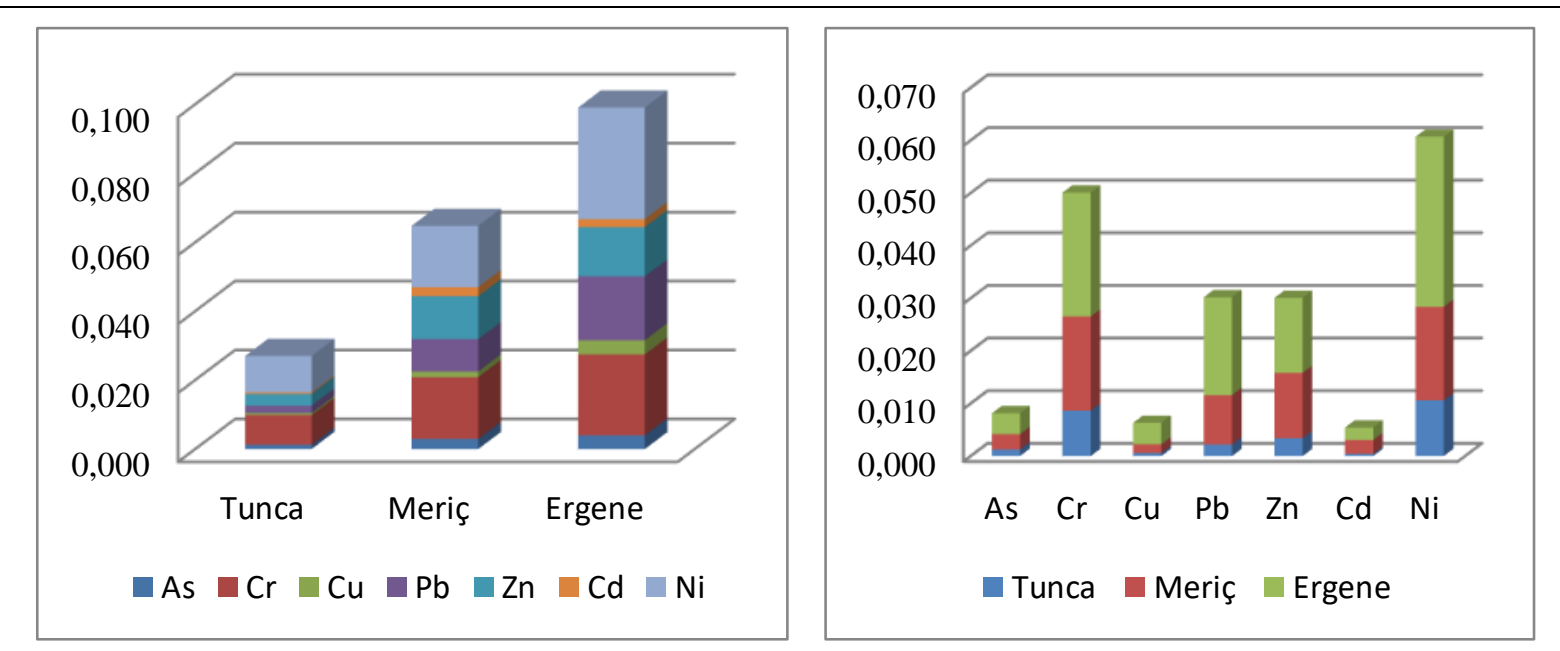

Source: Authors

\section{Conclusion}

In the present study, bio-ecological risk indices were used to evaluate the sediment quality of significant aquatic ecosystems within the Thrace Region of Turkey. According to the results of the RI, 
cadmium displayed the highest risk factor, and from the results of $\mathrm{mERM}-\mathrm{Q}$, nickel and chromium showed the highest risk factors for the region's rivers, Meriç, Ergene, and Tunca. The detected data in this study revealed agricultural and industrial activities are possible pollutant sources for this aquatic ecosystem. In addition, the present study shows the necessity of applying bio-ecological risk indices in freshwater sediment quality assessment studies.

\section{Acknowledgement}

The authors would like to thank to Trakya University TUTAGEM laboratories and also to Assoc. Prof. Dr. Oğuzhan DOĞANLAR for the chemical analysis in sediment samples.

\section{References}

ATSDR (Agency for Toxic Substances and Disease Registry) (2005). Toxicological Profile for Nickel. Atlanta, GA: U.S. Department of Health and Human Services.

ATSDR (Agency for Toxic Substances and Disease Registry) (2007). Toxicological Profile for Cadmium. Atlanta, GA: U.S. Department of Health and Human Services.

ATSDR (Agency for Toxic Substances and Disease Registry) (2008). Toxicological Profile for Chromium. Atlanta, GA: U.S. Department of Health and Human Services.

Çiçek, A., Tokatl, C., \& Köse, E. (2013). Ecological Risk Assessment of Heavy Metals in Sediment of Felent Stream (Sakarya River Basin, Turkey). Pakisan Journal of Zoology, 45 (5): 1335-1341.

Environmental Protection Agency (EPA) METHOD 3051. (1998). Microwave Assisted Acid Digestion of Sediments, Sludges, Soils, and Oils.

Environmental Protection Agency (EPA) METHOD 200.7. (2001). Determination Of Metals And Trace Elements In Water And Wastes by Inductively Coupled Plasma-Atomic Emission Spectrometry.

Environmental Protection Agency (EPA) (2005). Predicting Toxicity to Amphipods from Sediment Chemistry. EPA/600/R04/030, Washington, DC.

Farombi, E. O., Adelowo, O. A., \& Ajimoko. Y. R. (2007). Biomarkers of oxidative stress and heavy metal levels as indicators of environmental pollution in African Cat fish (Clarias gariepinus) from Nigeria ogun river. Int. J. Environ. Res. Public Health., 4 (2), 158-165.

Håkanson, L. (1980). An ecological risk index for aquatic pollution control of sediment ecological approach. Water Research $14,975 \mathrm{e} 1000$.

Hilton, J., Davison, W., \& Ochsenbein, U. (1985). A mathematical model for analysis of sediment coke data. Chemical Geology 48, 281e291.

Long, E.R., Ingersoll, C.G., \& MacDonald, D.D. (2005). Calculation and uses of mean sediment quality guideline quotients: a critical review. Environ. Sci. Technol. 40, 1726-1736.

Massoudieh, A., Bombardelli, F. A., \& Ginn, T. R. (2010). A biogeochemical model of contaminant fate and transport in river waters and sediments. J. Contam. Hydrol. 112, 103-117.

Tokatl, C. (2015). Assessment of the Water Quality in the Meriç River: As an Element of the Ecosystem in the Thrace Region of Turkey. Polish Journal of Environmental Studies, 24 (5): 2205-2211.

Yu, G. B., Liu, Y., Yua, S., Wuc, S.C., Leung A. O. W., Luo, X. S., Xua, B., Li, H. B., \& Wongc, M. H. (2011). Inconsistency and comprehensiveness of risk assessments for heavy metals in urban surface sediments. Chemosphere 85 , $1080-1087$. 